\title{
REPETIÇÃO SEM REPLICAÇÃO: ADAPTAÇÃO E FOCALIZAÇÃO EM WESTWORLD
}

Allana Dilene de Araújo de Miranda Luiz Antonio Mousinho Magalhães

Recebido em 04 out 2020. Allana Dilene de Araújo de Miranda

Aprovado em 08 fev 2021. Doutora em Letras pela Universidade Federal da Paraíba. Atua como técnica-administrativa junto à Universidade Federal da Paraíba.

https://orcid.org/0000-0003-4455-3363

https://www.allanadilene.com/

Luiz Antonio Mousinho Magalhães

Doutor em Teoria e história literária na Universidade Estadual de Campinas - UNICAMP.

Professor Titular da UFPB - Campus I, atuando nos cursos de graduação, mestrado e doutorado, nos Programas de Pós-Graduação em Letras e de Comunicação e Culturas Midiáticas.

https://orcid.org/0000-0002-7730-3195

Resumo: Este trabalho tem por objetivo analisar o seriado da HBO Westworld (Jonathan Nolan; Lisa Joy, 2016-) como adaptação do filme Westworld (Michael Crichton, 1973). A análise irá se deter especialmente nas duas primeiras temporadas, embora faça considerações envolvendo a terceira. Para tanto, iniciaremos com considerações a respeito do gênero ficção científica, e em seguida, lançaremos mão da teoria da adaptação de Linda Hutcheon (2013), pensando a adaptação pelo 
seu viés duplo - enquanto produto e processo de criação, relacionando-o à ideia de narrativa complexa, de Jason Mittel (2015). Também traçaremos paralelos com o modelo proposto por Robert Stam (2006), além das considerações discursivas acerca da focalização utilizada no seriado e no filme, baseando-se no modelo de estudo elaborado por Gérard Genette (2017) com complementações de Carlos Reis (2018). Este trabalho também traça alguns dos intertextos encontrados na série, identificando-os como índices que contribuem para a complexificação da narrativa, além de um discurso permeado por diversas referências aos videogames.

Palavras-chave: Westworld. Adaptação. Seriado. Ficção Científica.

Abstract: This paper aims to analyze Westworld (2016-), the series written and produced by Jonathan Nolan and Lisa Joy, as an adaptation of the film Westworld (Michael Crichton, 1973). It has as scope the first two seasons, although throughout the text some considerations about the third one. Understanding the objects as part of the science fiction larger context, the paper starts rising some characteristics about SF as a genre. Only then it discuss the theory of adaptation according Linda Hutcheon (2013), both as a process and as a product, relating it with Jason Mittel's (2015) idea of complex narrative. The paper also considers the theoretical model proposed by Robert Stam (2006) to study film adaptations, and also analyzes the focalization on film and series alike, based on Gérard Genette's (2017) study, complemented by Carlos Reis (2018). The present study also points out some of the intertexts identified along the series, including those related to the language of games, suggesting them as characteristics that builds up, among other mechanisms, the narrative complexification.

Keywords: Westworld. Adaptation. Series. Science Fiction. 


\section{REPETIÇÃO ENQUANTO RECORRÊNCIA DE TEMAS - AS FRONTEIRAS DÚBIAS DA FICÇÃO CIENTÍFICA}

Os dilemas em torno das fronteiras ambíguas entre o "eu" e o "outro" habitam a ficção científica ${ }^{1}$ desde a sua gênese, como pode ser visto no romance Frankenstein: ou o Prometeus moderno, de Mary Shelley. Tido como texto inicial do gênero por alguns estudiosos (CLUTE; NICHOLLS, 1995), o romance lança as bases para um dos grandes questionamentos da ficção científica que viria nos séculos seguintes: o que, de fato, define um ser humano?

Tal embate ganhou pertinência e perenidade no gênero, como é possível ver nas obras de FC nos mais diversos meios: os robôs de Isaac Asimov (1920-1992), Blade runner (Ridley Scott, 1982), Ghost in the shell (Mamoru Oshii, 1995), Her (Spike Jonze, 2013), bem como o objeto deste trabalho, Westworld (Jonathan Nolan e Lisa Joy, 2016). Além da recorrência do tema, materializado na figura da inteligência artificial que faz questionar a própria definição de humanidade, há outros aspectos em relação à ficção científica enquanto gênero que se farão importantes ao longo da análise.

Ideia comumente propagada é aquela de que a ficção científica se volta para o futuro e as possíveis consequências do avanço técnico-científico. Adriana Amaral, no entanto, destaca que o gênero é uma metáfora do presente, e isso "pontua as histórias, seja através de críticas, seja através de paródias" (AMARAL, 2006, p. 68). Para Adam Roberts, "a FC não nos projeta para o futuro, ela nos relata histórias sobre nosso presente, e mais importante, sobre o passado que nos levou a esse presente. Contraintuitivamente, FC

1 Doravante podendo ser substituída pela sigla "FC". 
é um modo historiográfico, um meio de escrever simbolicamente sobre história" (ROBERTS, 2000, p. 35-36, grifo do autor).

Fátima Regis (2011) reforça essa tese. Para a autora, o futuro representado pela ficção científica

é sempre "o futuro do presente". As possibilidades de futuro, os sonhos e os pesadelos mudam de acordo com o momento histórico, assim como a experiência de espaço, a noção de tempo - e de um tempo porvir - também se transformam segundo o contexto em que se vive. (RÉGIS, 2011, p. 182)

Essa tendência historiográfica de olhar para o passado, refletir sobre o presente e imaginar certos futuros pode conferir à FC certo caráter nostálgico, deixando-se notar ora de modo mais sutil, com a adoção de uma estética retrofuturista nos figurinos de um filme (como em Blade Runner, 1982, Ridley Scott), ou de maneiras mais explícitas, como a série de romances Duna, de Frank Herbert. Quadrinhos como Flash Gordon (Alex Raymon e Don Moore, 1934) também trazem revisitações de elementos dos romances de capa e espada, deixando latente tal característica no gênero.

Embora seja pensada primordialmente enquanto ficção e, assim, atenta mais à coerência interna e à verossimilhança narrativa (TAVARES, 1992, p. 24), não se deve perder de vista o caráter técnico-científico do gênero. Para Darko Suvin (1979), os textos de ficção científica são baseados em um novum - um ponto de partida que seja produto da cultura racional, capaz de diferenciar o mundo ficcional daquele em que vivemos, e que possibilite certo estranhamento cognitivo. Esses nova, embora 
não precisem ser propriamente científicos, não raro permeiam discussões pseudocientíficas (ROBERTS, 2000, p. 8, tradução nossa), tornando os textos "baseados em um discurso de possibilidade, que normalmente é o da ciência ou da tecnologia, e que torna a diferença material no lugar de uma diferença imaginativa" (ROBERTS, 2000, p. 7, tradução nossa).

Essa diferença material apontada por Adam Roberts faz da ficção científica um gênero simbolista, isto é, que se utiliza de imagens e símbolos para representarem ideias. A FC seria, portanto, capaz de reconfigurar tais símbolos para nossa era materialista, tornando-os físicos (2000, p. 18), corporificando-os. Ao invés de tratar do Outro, ela corporifica tal imagem na figura da vida alienígena; ao levantar discussões sobre a automação e o avanço das inteligências artificiais, a ficção científica cria histórias materializando suas elucubrações nas figuras de robôs ou inteligências artificiais imateriais que pensam e agem por eles mesmos.

Fátima Regis, por seu turno, vê as narrativas de FC como aptas a problematizar "as fronteiras entre subjetividade, tecnociência e espaço-tempo como estratégia de interrogar o humano" (2011, p. 12). A autora não nega o dado tecnológico do gênero, nem o caráter especulativo acerca das mudanças empreendidas por possíveis avanços, mas aponta os problemas de limitar o estudo apenas às mudanças ou ao caráter sociotécnico (2011, p. 25-27). Em suas palavras, "a ficção científica nunca se rendeu às barreiras epistemológicas do pensamento moderno. Por isso, sempre escapou às tentativas de classificação dessa ordem, tornando-se um gênero que se vale de múltiplos saberes" (REGIS, 2011, p. 24). 
A autora ainda destaca que a ficção científica enquanto gênero consciente de si teve as condições propícias para seu advento na modernidade. Com o surgimento de modelos científicos baseados na realidade exterior e, portanto, necessitados de contexto histórico e cultural, percebe-se a "finitude e a efemeridade humana" (REGIS, p. 35). Mais importante, o modo de saber moderno não apenas interioriza o processo científico, como também,

abre uma distância no interior do sujeito. [...] Ao mesmo tempo que confere profundidade subjetiva ao homem, o pensamento moderno estabelece como tarefa alcançar o seu outro eu. Cria-se um ideal de sujeito humano universal como aquele que está presente a si, autossuficiente, racional e possuidor de livre arbítrio. A defasagem entre o eu "atual" e o eu civilizado e transparente a si, a distância entre a sociedade atual e a democracia, será eliminada com o tempo. (REGIS, 2011, p. 36)

Desta forma, o pensamento moderno e as revoluções que iniciaram a Modernidade explicitam o imbricamento irreversível entre um sujeito autônomo, parte do meio e por ele determinado, e uma relação com o tempo, "que concebe o futuro como produto das mudanças sociais no presente" (REGIS, 2011, p. 40). Mudanças essas que partirão do trabalho dos cidadãos pensantes. O tempo do presente será sempre imperfeito, enquanto o futuro traz a esperança de dias e sujeitos melhores.

Para Fátima Regis, porém, a Modernidade não é capaz de pensar a FC, pois seus parâmetros estabelecem fronteiras entre homens, animais e máquinas, tratando "a tecnologia como instrumento de alienação ou libertação do indivíduo, mas nunca como algo que se 
imbrica com os modos de subjetivação e faz repensar os limites do ser humano" (REGIS, 2011, p. 41).

Os objetos do presente trabalho trazem em sua constituição muito dos elementos apontados até então. A narrativa primeira é o longa-metragem Westworld (Michael Crichton, 1973), que usa como premissa um parque temático no qual o visitante imerge em um cenário semelhante aos filmes de faroeste. O parque é populado por robôs indistinguíveis de humanos, e os elementos típicos das narrativas de faroeste - caçadas por recompensas, brigas em saloons - podem ser vivenciados pelos visitantes, de maneira razoavelmente segura. Essa situação muda quando o protagonista, Peter, passa a ser perseguido pelo Pistoleiro, e todas as máquinas começam a se rebelar contra os visitantes humanos e a equipe técnica. Já a série homônima é dirigida por Jonathan Nolan e Lisa Joy, e sua primeira temporada data de 2016. Aqui, a premissa é semelhante: há um parque temático de enormes proporções no qual os visitantes poderão desfrutar e imergir nas mais diversas narrativas comuns à temática faroeste. Populados por androides de perfeita aparência humana, uma intrincada cadeia de eventos leva ao ganho de consciência das máquinas, que acabam por se rebelar contra seus criadores. Entretanto, diferenças sensíveis entre as duas obras se fazem perceber, abrangendo desde a inserção de novos personagens, com suas próprias subtramas, à adequação tecnológica ao presente contexto.

Acerca dos elementos de ficção científica apontados, percebem-se os índices de nostalgia, materialidade simbólica e diferentes visões de subjetividade. Quanto à nostalgia, é possível notá-la claramente em ambas as obras, tanto a fílmica quanto 
a seriada. Tal mundo é habitado por androides de aparência e trejeitos indistinguíveis de suas contrapartes humanas, tudo para proporcionar aos visitantes uma experiência completamente imersiva e semelhante à imaginária nos tempos da exploração das fronteiras selvagens. Um mundo de possibilidades, no qual os pagantes podem fazer o que bem entenderem sem consequências reais - androides que eventualmente morrerem serão consertados e terão as memórias reiniciadas, e assim, quaisquer crimes cometidos contra eles serão impunes.

Nota-se, assim, a oferta de uma ficção interna à diegese - a da terra cheia de maravilhas e pronta para ser desbravada, "em que se pode ser quem você quiser". O produto ofertado é o escape da realidade para uma simulação espraiada: em uma sociedade onde tudo é mapeado e vigiado por sistemas de vigilância, câmeras e satélites, vive-se em um lugar onde tudo é conhecido e não há nenhuma nova fronteira a ser explorada; a humanidade teria alcançado seu ápice. Assim, o parque atende à nostalgia de um tempo no qual havia algo a ser descoberto, feitos a serem realizados. O que acontece é um regresso não ao Velho Oeste histórico, mas a um passado mítico que permite aos visitantes vivenciarem possibilidades de uma nova fronteira de maneira fantasiosa, sem consequências palpáveis. Para Luiz Carlos de Oliveira Junior, o parque é "o infantilismo regressivo da Disneylândia somado à permissividade 'adulta' de Las Vegas. [...] 0 parque congela o Velho Oeste como imagem, situando-o ao abrigo das transformações históricas que Ihe puseram fim" (2020, p. 110).

2 Na terceira temporada da série, o espaço narrativo é profundamente alterado. Os androides deixam o parque e estão no mundo dos humanos. Os papéis de explorador se invertem: é agora a vida artificial que tenta desbravar as dinâmicas e os espaços habitados por humanos, passando-se por eles e usando artifícios para manipular as tecnologias. 
Aliado à alta tecnologia, esse índice nostálgico não deixa de tecer comentários a respeito do contexto de produção dos textos. Na época do filme de Michael Crichton (lançado em 1973), predominava na produção de ficção científica certa paranoia tecnológica, e grande presença de narrativas de FC que colocavam em xeque a própria natureza da realidade. Depois da Segunda Guerra e suas bombas atômicas, preponderava certo temor ante os avanços científicos, o que se materializava no gênero através de "pessimismo e a paranoia em relação às fronteiras da realidade, assim como [d]as relações de poder", aparecendo "em forma de histórias violentas e sexualizadas, integradas à tecnologia, não como máquinas para viagens às estrelas, mas inseridas no cotidiano do indivíduo" (AMARAL, 2006, p. 72). Na narrativa fílmica, os robôs materializam esses temores e questionamentos: a experiência no parque é, a um só tempo, tão real e inconsequente que, quando se torna uma ameaça factual, choca pela surpresa; os seres humanos, incrédulos, não conseguem sequer explicar o que está acontecendo. A ciência não consegue prover as respostas necessárias para separar mais uma vez as fronteiras.

No mundo contemporâneo, a tecnologia permeia todas as atividades do cotidiano das grandes cidades, mediando a maioria das comunicações; grandes empresas coletam dados de navegação e compra, criando bolhas virtuais que guiam e limitam o acesso à informação. As distinções entre "virtual" e "presencial", especialmente em períodos de isolamento social recomendados pelos órgãos internacionais de saúde, tornam-se ainda mais imprecisas, posto que as comunicações afetivas com familiares e amigos passam a ser mediadas através de dispositivos. 
É com condições históricas, sociais e tecnológicas mais afins a esse contexto que o seriado Westworld dialoga. Os androides de aparência humana materializam essas discussões, questionando a validade tanto das experiências por eles vivenciadas no parque quanto as dos convidados. "Se você não consegue distinguir um do outro, que diferença faz?", diz Angela, a anfitriã maquínica que recepciona os visitantes do parque.

Como último dos elementos mencionados, o conflito que move a trama em ambas as mídias, mas especialmente na série, dá-se exatamente na fronteira que põe em dúvida os limites e definições de humanidade. O filme de Michael Crichton abre com uma peça publicitária, na qual um suposto repórter entrevista pessoas recém-chegadas dos parques da Delos. Todas elas são unânimes em descrever as maravilhas que podem ser vistas e vivenciadas, e um visitante em particular exclama, extasiado: "Eu matei seis pessoas! Quer dizer, eu sei que não eram pessoas, eu acho que não eram". Outra visitante, ao ser perguntada do que mais gostou em sua visita ao Mundo Romano ${ }^{3}$, é rápida em responder: "os homens".

Há aqui uma clara objetificação dos androides, que são vistos como nada além de propriedade, máquinas com um propósito específico de entretenimento, que virá, normalmente, na forma de repetidas mortes e outras violências cometidas pelos visitantes. Acompanhando o protagonista Peter Martin (Richard Benjamin), somos levados a questionar as fronteiras de realidade mais de uma vez, por exemplo, quando ele pergunta diante de uma androideprostituta: "você tem certeza de que ela não é uma pessoa?". o

3 Ambas as narrativas supõem que o parque tem diferentes áreas, como brinquedos temáticos específicos, que vão de elementos de fantasia medieval ou contos de cavalaria a um suposto Japão feudal. 
personagem, porém, não demora a se adaptar à lógica do parque e a naturalizar os androides como não-seres, e sofre as consequências de seus atos quando a lógica do "jogo" vira contra si. Os androides do filme, no entanto, não parecem ser capazes de deixar sua condição de "máquinas"; sem os funcionários para cuidarem de sua manutenção, eles terminam a narrativa sem bateria, como brinquedos abandonados ${ }^{4}$.

Na série de Jonathan Nolan e Lisa Joy, esse imbricamento de fronteiras é ainda mais notório. Um dos personagens se apaixona por uma anfitriã, termo usado na série para se referir aos androides, e é por ela correspondido; o visitante chega a afirmar que nunca teria experenciado algo tão real quanto aquele sentimento, o que depois é esfacelado quando ele percebe que as memórias de sua parceira foram reiniciadas. Além disso, outros anfitriões, ao serem capazes de se lembrar de suas "vidas passadas", começam a adquirir consciência de si mesmos, tornando-se cientes das violências diversas que sofreram.

A série lança mão de outros elementos discursivos que servirão tanto para lembrar aos anfitriões de suas condições de objeto quanto como representações de tendências tecnológicas atualmente vivenciadas: aparelhos que respondem a comandos de voz, tablets finos e dobráveis com tecnologia touchscreen, substituindo as enormes e pesadas centrais de informação; vidros transparentes que dão um ar "futurista", mas que também propiciam um eterno estado de vigilância através de câmeras

4 Tais comparações visuais se fazem presentes em outros títulos de ficção científica, como Blade Runner (1982, Ridley Scott): quando não é o enredo que lembra aos replicantes sua condição "de máquina", o espaço ao seu redor o faz, aproximando-os de manequins ou de bonecos de aparência bem próxima à de humanos. 
invisíveis. Os anfitriões são, antes de tudo, propriedade de uma empresa privada e deverão obedecer aos seus comandos sem questionamentos, e, enquanto posses, devem ser conservados e vigiados o tempo todo, sob a desculpa de que são cuidados para proteção de propriedade intelectual.

Ao terem suas memórias apagadas, os anfitriões retornam aos chamados loops narrativos aos quais foram designados. 0 espectador vê cenas se repetindo, mas com camadas de significado se acumulando sobre elas, como a poeira da paisagem desértica. Dolores (Evan Rachel Wood) diz, repetidas vezes, que escolheu "ver a beleza deste mundo", mas, à medida em que ela vai se lembrando dos eventos de suas muitas vidas, sua fala vai sofrendo alterações e ganhando novos sentidos, demonstrando tanto as mudanças que a personagem sofre no decorrer da trama quanto os novos significados que são atribuídos às experiências vivenciadas - a repetição existe, mas ela não é mera replicação. Pensando na produção audiovisual como um todo, a repetição é exatamente um dos principais atrativos das adaptações, para Linda Hutcheon (2013). Vejamos agora como as considerações sobre adaptação enquanto produto e processo criativo têm a contribuir para a análise dos objetos em questão.

\section{REPETIÇÃO ENQUANTO ADAPTAÇÃO - O PRAZER DE EXPERIMENTAR O CONHECIDO}

Para Linda Hutcheon, a adaptação oferece um prazer inerente ao tipo de produto apresentado: o da experiência do reconhecimento com a possibilidade de inovação (p. 25). Ela seria, portanto, uma "repetição sem replicação" (2013, p. 28) e, 
desta forma, para pensar o texto adaptado enquanto adaptação, devemos analisá-lo sob duas perspectivas: a adaptação como produto e como processo de criação/recepção (2013, p. 39).

Ao ver a adaptação como um produto, deve-se considerála como uma tradução, "mas num sentido bem específico: como transmutação ou transcodificação, ou seja, como necessariamente uma recodificação num novo conjunto de convenções e signos" (HUTCHEON, 2013, p. 40) de um texto já existente. Logo, a intertextualidade será uma característica inerente à adaptação. Obviamente, o novo texto poderá - e deverá, certas vezes ser analisado como a obra autônoma que é. Entretanto, para que seja tratado como adaptação, deverá ser experimentado em consonância com o texto fonte.

Isso não quer dizer, no entanto, que a fidelidade deva ser um critério único de julgamento e análise. Análoga à tradução, a adaptação literal inexiste, e, caso existisse, não teria valor (HUTCHEON, 2013, p. 39). A própria palavra nos remete a esse campo semântico: adaptar é modificar, reformatar um objeto de acordo com as necessidades. Sempre haverá mudanças no processo de adaptação, cortes e acréscimos, e essas modificações terão influência de diversos fatores, presentes no processo de criação.

Enquanto processo criativo, relembramos a colocação anterior: adaptação é repetição sem replicação. Adaptar está longe de ser apenas copiar, podendo ser um ato de criação própria; é um "processo de apropriação, de tomada de posse da história de outra pessoa, que é filtrada, de certo modo, por sua própria 
sensibilidade, interesse e talento de alguém" (HUTCHEON, 2013, p. 43). Isso quer dizer que não apenas

a mudança é inevitável, mas que haverá também diferentes causas possíveis para essa mudança durante o processo de adaptação, resultantes, entre outros, das exigências da forma, do indivíduo que adapta, do público em particular e, agora, dos contextos de recepção e criação. (HUTCHEON, 2013, p. 192)

Ignorar o apelo econômico em torno das adaptações seria eliminar um fator importante: a possibilidade de lidar com o texto conhecido, trazendo à tona a lembrança do texto anterior, tendo como acréscimo a possibilidade do novo, atrai um público cativo (2013, p. 126) que certamente trará retorno financeiro à empreitada, além de atrair novos consumidores. Linda Hutcheon menciona ainda o capital cultural (2013, p. 91) que uma adaptação carrega por mencionar o nome do autor do texto base, ou uma obra já famosa e consolidada na mente do público.

Além disso, existem as razões pessoais e políticas. Os adaptadores "não apenas interpretam [uma] obra, mas também assumem uma posição diante dela" (HUTCHEON, 2013, p. 133). O adaptador pode resolver prestar uma homenagem ao trabalho em questão, como também oferecer uma visão crítica, seja a respeito do texto adaptado ou do próprio contexto de produção. Como exemplo, podemos citar o filme Apocalypse now (Francis Ford Copolla, 1979), que é uma adaptação do livro Heart of darkness, de Joseph Conrad, publicado pela primeira vez em 1899. Copolla atualizou o momento histórico e criou um novo texto, visando a um público diferente, embora oferecendo uma visão igualmente crítica a respeito da situação retratada. 
Enquanto processo, a adaptação também deve ser percebida pela perspectiva da recepção. Experimentar a adaptação, como já mencionamos, é prazeroso pela "mistura de repetição com diferença, de familiaridade com novidade" (HUTCHEON, 2013, p. 158). E, para que o público tenha a experiência da adaptação como tal, é necessário que seja conhecedor do texto base (2013, p. 166), pois terá a sensação de "conforto, um entendimento mais amplo e a confiança que advém da sensação de conhecer o que está por vir" (2013, p. 158). Essa expectativa em torno da nova obra pode, no entanto, ser negativa para o produto final: o espectador pode facilmente se desapontar caso a adaptação não seja fiel ou não fique à altura de sua expectativa do texto fonte.

O contexto também dialoga com a produção de uma obra, influenciando-a e sendo por ela influenciado. Para Antonio Candido,

a arte é social nos dois sentidos: depende da ação de fatores do meio, que se exprimem na obra em graus diversos de sublimação; e produz sobre um indivíduo um efeito prático, modificando a sua conduta e percepção do mundo, ou reforçando neles o sentimento dos valores sociais. Isto decorre da própria natureza da obra e independe do grau de consciência que possam ter a respeito os artistas e receptores de arte. (CANDIDO, 1980, p. 20-21)

Por contexto, além dos elementos ideológicos e sociais, que sempre se fazem presentes no processo de criação de qualquer obra, Linda Hutcheon (2013, p. 192-193) considera também a materialidade da obra e da mídia em questão, como certos avanços tecnológicos influenciando a produção de um filme, por exemplo. Elementos reais e palpáveis podem atuar no processo de criação de 
uma obra, conforme podemos ver nos objetos analisados: se o filme de Michael Crichton, para representar a visão computadorizada do Pistoleiro, utiliza imagens pixelizadas que atualmente parecem obsoletas e inadequadas, a série produzida pela HBO conta com efeitos especiais de ponta na representação computadorizada do parque, na sala de controle central.

Considerando a perspectiva "palimpsestuosa" traçada por Linda Hutcheon (2013, p. 21), pretende-se fazer uma análise preponderantemente narratológica dos objetos. Para Robert Stam, uma análise dessa natureza deve observar que alterações foram feitas e, "mais importante, por quê?" (2006, p. 40-41). Além disso, "uma narratologia comparativa da adaptação também examina as formas como as adaptações adicionam, eliminam ou condensam personagens. [...] O problema que importa para os estudos da adaptação é que princípio guia o processo de seleção" (2006, p. 41). Buscar discernir os sentidos e os efeitos dessas alterações no novo texto, levando em conta elementos como o contexto e questões mercadológicas é o que pretendemos fazer ao longo deste trabalho. Procuramos perceber os elementos em comum, investigar os sentidos impressos na obra com esse movimento e como as adaptações repetem-se sem se replicar.

Notam-se, entre o filme de Michael Crichton (Westworld, 1973) e a série televisiva, profundas alterações no enredo, o que não deveria surpreender quando consideramos os contextos distintos de produção. Embora ambos os textos partam de premissas semelhantes, desenvolvem-nas de maneiras diversas. Conforme poderemos ver ao longo da análise, o regime de focalização adotado nos dois textos altera profundamente os sentidos produzidos. 
Destaca-se ainda um dado, relacionado ao tempo narrativo: a linearidade presente no filme e ausente na série.

No filme, o enredo pode ser condensado nos seguintes termos: o protagonista Peter Martin chega ao parque, começa a se envolver com as atividades do lugar e depois inicia uma fuga por sua sobrevivência, pois os androides começam a atacar de maneira indiscriminada. Peter é perseguido pelo Pistoleiro (Yul Brynner), personagem que traja sempre vestes pretas e que representa duplamente uma ameaça: no plano do enredo, por ser o androide de motivações desconhecidas, e no plano iconográfico, por vestir preto e ser interpretado por um ator de etnia não-americana.

Essa estrutura linear é substituída no seriado, que opta por utilizar uma poética que Jason Mittel $^{5}$ chama de complexa. Nas palavras do autor, a complexidade narrativa "redefine formas episódicas sob a influência da narração seriada [...]. A [narrativa] de TV complexa emprega toda uma sorte de técnicas seriadas, com a suposição subjacente que uma série é uma narrativa cumulativa que se constrói ao longo do tempo" (2015, p. 418-422, tradução nossa).

Na poética da narrativa seriada complexa, Mittel (2015, p. 539, tradução nossa) distingue, dentre os eventos que movem a trama, dois tipos: aqueles de afirmação narrativa e os de enigmas narrativos (narrative statements and narrative enigmas, no original). Os primeiros estão relacionados ao andamento da trama, levantando questões sobre as possíveis consequências em termos de causalidade. Não há, em geral, ambiguidade sobre o 5 Este livro foi consultado em sua edição digital para leitor eletrônico; as indicações após o "p." não correspondem à paginação de um livro físico, mas à posição das referências na navegação do e-book. 
que teria acontecido. Os enigmas narrativos, por sua vez, levantam questionamentos a respeito de sua veracidade, de quando ou mesmo se teriam acontecido, além de contribuírem para um outro tipo de engajamento do público com o texto, com o surgimento do que o autor chama de forensic fandom, pessoas que se envolvem em discussões através de redes sociais e fóruns, onde trocam hipóteses e analisam de maneira mais minuciosa detalhes como diálogos entre personagens.

Enquanto adaptação, o seriado da HBO optou por aderir à complexidade narrativa. Para tanto, a série explora diferentes temporalidades, dando por vezes a ilusão de que todos os eventos acontecem simultaneamente, quando, na verdade, alguns deles são narrados em flashback sem sinalização específica. Além dessa relação temporal que causa um efeito de confusão compartilhado entre espectador e personagens, Sílvio Anaz percebe que cada linha temporal, presente e passado, "contém ainda dois tipos de temporalidades operando de forma entrelaçada em seu interior: o tempo circular, dos androides, e o linear, dos humanos" (ANAZ, 2018, p. 7).

Essa distinção da percepção do tempo entre as duas espécies de personagens no seriado reforça o dado de adaptação apontado inicialmente. Conforme discutido mais adiante, o regime de focalização também é um recurso narrativo operacionalizado a favor da complexidade narrativa na série. Já apontamos que no texto fílmico o tempo da narrativa é linear, com eventos acontecendo em sucessão; e de maneira não surpreendente, a narrativa fílmica é focalizada sob o filtro informacional de personagens humanos, ou seja, conforme o conceito de focalização (GENETTE, 2017), os 
eventos narrativos são filtrados pela maneira como um personagem ou um grupo de personagens os percebem. O texto é ampliado no enredo, no tempo de discurso e em possibilidades de significação com a abertura da série para personagens focalizadores androides.

As duas obras apresentam ainda diferentes espaços narrativos, que atuam para demarcar tanto a liberdade de locomoção dos personagens androides quanto para criar certos códigos de comportamento nesses espaços. O texto fílmico representa ao menos dois importantes espaços: o da administração do parque, onde os cientistas e técnicos consertam e melhoram os androides, e que também serve de transição para os visitantes; e o cenográfico, onde a regra é a imersão completa nas propostas de diversão do lugar, o que inclui as vestimentas e a manutenção de uma "ilusão" hollywoodiana - a retirada dos androides para manutenção se dá quando os convidados estão supostamente dormindo, para que a simulação não perca seu encanto.

Tanto a ilusão clássica quanto as regras de comportamento ditadas pelos espaços são quebradas ao longo do filme. Durante a perseguição que caracteriza o último ato, Peter encontra um funcionário do parque usando trajes de segurança, que dá informações sobre as últimas melhorias pelas quais o Pistoleiro passou, pouco antes de ser morto. Em sua fuga, Martin passa ainda pelo Mundo Romano, usando os túneis de manutenção chamando a atenção para o caráter de artefato construído do parque - e termina sua jornada no Mundo Medieval, onde é enganado uma vez mais, quando dá água a uma androide e a vê entrar em curto-circuito. 
Distribuição espacial semelhante aparece na série, conforme discutido por Ś́lvio Anaz (2018, p. 11) quando analisa a topologia diegética. Nas palavras do autor, "há uma separação dos universos ficcional e não-ficcional", reforçada por outros elementos discursivos, como os figurinos adotados, as atuações dos personagens. Assim, quando esses espaços são transgredidos pelos humanos ou androides ao longo da narrativa, essas ações causam tanto estranhamento, como pessoas andando com trajes comuns ou de manutenção no meio do parque, quanto efeito dramático por exemplo, quando Maeve, agora já consciente de sua condição, começa a transitar pela administração do parque, conhecendo as entranhas do que alguns dos anfitriões chamam de "deuses".

Tal separação entre ficcional e não ficcional é "um redobramento espacial" (ANAZ, 2018, p. 11), que, assim como outros elementos, atua como índice de reflexividade narrativa. A série, de maneira muito mais crucial que o filme, revela várias vezes seu caráter de constructo fictício, como quando da presença de Robert Ford (Anthony Hopkins), o idealizador do parque e personagem que controla todos os androides; Lee Sizemore (Simon Quarterman), um dos escritores que também lembra os anfitriões da artificialidade de suas memórias e de seus ciclos narrativos fechados. Essa reflexividade se acumula aos outros elementos que constituem a poética complexa da série, tendência que vem se mostrando cada vez mais presente nas produções seriadas mais recentes no mercado internacional.

Entendendo que em ambos os objetos estudados aqui a focalização atua de maneira profunda tanto na estruturação quanto como importante construtor de sentido, inclusive na 
complexificação da narrativa seriada, iremos discutir mais detidamente como esse aspecto é trabalhado nas obras.

\section{REPETIÇÃO ENQUANTO ACÚMULO DE SENTIDOS - FOCALIZAÇÃO E SEUS USOS}

Para tratar da questão do ponto de vista, ou foco narrativo, tomamos por base a teorização de Gerárd Genette, que, sob a metáfora da perspectiva narrativa, prefere a expressão focalização, definida como "modo de regulação da informação que procede da escolha ou não de um 'ponto de vista'" (GENETTE, 2017, p. 259). Discutindo o conceito, Carlos Reis traz as seguintes clarificações:

Primeiro: a focalização é um recurso dinâmico, uma vez que não se fixa obrigatoriamente num regime específico, nem numa só personagem, tendendo a oscilar entre vários pontos focais. Segundo: faz parte desse dinamismo a inscrição, no discurso da focalização, de elementos estilísticos (imagens, metáforas, etc.) que, no plano fraseológico, traduzem posições afetivas, emotivas e ideológicas das personagens em focalização ou do narrador. (REIS, 2018, p. 173)

Genette divide a focalização em três tipos: a focalização zero ou narrativa não focalizada, a interna e a externa (2017, p. 263264). A primeira refere-se ao uso de foco inespecífico, sendo equivalente à focalização onisciente, conforme Carlos Reis. Além do "conhecimento potencialmente ilimitado do narrador acerca da história" (2018, p. 180), o estudioso português prefere o termo onisciente por entender que a expressão genettiana pode corresponder àquelas obras "que não recorrem de forma significativa a procedimentos de focalização" (2018, p. 181). 
O segundo tipo, a focalização interna, limita-se ao campo de consciência de uma personagem ou de várias, podendo aparecer como focalização fixa, múltipla ou variável (GENETTE, 2017, p. 264). A focalização interna fixa se centraliza em um único personagem, podendo haver momentâneas alterações (REIS, 2018, p. 178), enquanto a variável consta de um núcleo fixo de personagens focalizadores. A focalização interna múltipla, conforme apresentada por Genette (2017, p. 264), pode ser exemplificada no romance epistolar, posto que vários personagens servem como focalizadores, às vezes debruçando-se sobre o mesmo fato, o que pode ser utilizado para lançar dúvidas sobre dados de enredo. Por fim, a focalização externa é aquela em que "o herói age diante de nós sem que sejamos convidados a seguir seus pensamentos ou ideias" (GENETTE, 2017, p. 264). Destacamos, porém, a ressalva em relação a esse aspecto no que se refere ao específico do discurso cinematográfico. Para Robert Burgoyne, é difícil imaginar no cinema qualquer apresentação de personagens que não inclua indicações "sobre seus sentimentos, pensamentos e emoções" (1999, p. 92), características que aproximariam a obra de uma focalização interna.

No caso da focalização interna, recebemos a informação diegética através da percepção de um personagem, com acesso aos seus pensamentos e impressões. Interessa-nos analisar "a maneira através da qual o personagem serve como centro de interesse psicológico e emocional" (BURGOYNE, 1999, p. 91). Em relação aos outros personagens da história, contudo, há a possibilidade de estarmos diante de um foco externo - de maneira análoga ao conhecimento das outras pessoas na vida real. $\mathrm{Na}$ narrativa onisciente, teremos a impressão do domínio completo da 
informação. Na focalização interna variável, teremos uma variedade de pontos de vista, o que pode fazer com que a interpretação a respeito das personagens e eventos varie com o decorrer da história.

$\mathrm{Na}$ literatura, duas obras brasileiras representam bem essa ambiguidade que a mesma personagem pode adquirir: Dom Casmurro, de Machado de Assis, e Olhar de Capitu, de Fernando Sabino. Enquanto o primeiro romance nos apresenta Capitu estritamente sob o olhar de Bentinho, o segundo busca adotar uma focalização mais afastada e impessoal. O conjunto das duas obras cria uma visão diversificada da mesma personagem, dando margem a interpretações variantes.

Um ponto importante que deve ser salientado na formulação de Genette (2017) é que ele separa a instância da voz narrativa do ponto de vista. A voz, para Genette, é aquele aspecto "da ação verbal considerada nas suas relações com o sujeito - não sendo esse sujeito aqui somente aquele que sofre ou exerce a ação, mas também aquele que a relata" (2017, p. 289). Em outras palavras, a voz tem mais a ver com a instância que relata, ou o narrador. $\mathrm{O}$ estudioso acrescenta que, ao longo da narrativa, o narrador pode variar internamente (2017, p. 290), como um narrador onisciente que incorpora as palavras de um personagem contando uma outra história. Para ilustrar, Genette cita como exemplo a Odisseia, que dá voz ao personagem Ulisses quando este conta sua história aos Feácios. Já o ponto de vista está relacionado ao personagem focalizador, que servirá como filtro informativo. Por vezes, o narrador pode ser aquele que detém a focalização (exemplo famoso é o Dr. Watson, parceiro e narrador das histórias de Sherlock Holmes). Os objetos analisados neste trabalho se utilizam dos regimes de 
focalização, com personagens focalizadores identificáveis, para a criação de efeitos de sentido específicos, como confusão temporal, mistério e surpresa.

A formulação de Genette permite uma maior distinção entre categorias muitas vezes colocadas sob o mesmo conceito do foco narrativo: instâncias como o narrador e personagem focalizador por vezes são tomadas como o mesmo elemento, quando na verdade não o são. A série de romances de fantasia As crônicas de gelo $e$ fogo, de George Martin, é estruturada em capítulos que alternam os personagens focalizadores, mas o narrador, porém, é externo à diegese, não podendo as duas instâncias ser confundidas. O já citado romance Frankenstein, de Mary Shelley, trabalha com uma narrativa emoldurada, que se inicia com as cartas de um explorador para sua irmã, para dar a voz ao cientista Victor Frankenstein, e voltar à primeira instância do explorador.

Tendo por objetivo verificar a função construtora de sentido que focalização adquire, notamos que tanto o filme de Michael Crichton quanto o seriado de Jonathan Nolan e Lisa Joy estão "impregnados" por seus respectivos pontos de vista, e reconhecer essas marcas discursivas mostrou-se necessário para o processo de análise.

Muito, porém, se diz em um texto (literário, fílmico) para além do regime de focalização. Para a compreensão ampla de uma obra, dados como a focalização devem ser analisados em conjunto com outros elementos constitutivos, tendo em vista também suas funções narrativas e correlações internas e externas, como o contexto de produção, recepção e a resposta social (BRAGA, 2006, p. 22). 
É através do uso da focalização que a série consegue ampliar elementos presentes no texto-fonte, especialmente no que diz respeito à construção das personagens androides. No filme de Michael Crichton, a focalização está quase que restrita a um personagem conhecidamente humano, Peter Martin, com breves momentos de alternância entre ele e o supervisor do parque, também humano. Lançando mão de uma máxima comumente utilizada quando se tratando de histórias de algum cunho fantástico, Peter é o personagem ignorante de toda a situação, atuando como meio de projeção do espectador: aprende-se junto com ele sobre o novo mundo que se desvela diante de seus olhos. É sob seu filtro perceptivo que conhecemos o parque e todas as suas potencialidades.

Peter é exibido chegando ao parque junto de um amigo, conversando animadamente sobre o que poderiam encontrar lá. Através de um vídeo institucional, ele apreende as informações básicas e é transportado para um prédio de corredores de linhas retas e lisas, onde são cedidos seus equipamentos básicos para a experiência imersiva no parque: roupas típicas associadas à iconografia do Velho Oeste cinematográfico e, claro, uma arma com coldre preso à cintura. Como alguém que ainda está aprendendo as regras de um novo jogo, o protagonista demonstra certo desconforto diante da ideia de atirar em alguém que pareça tão humano ("Como eu vou saber que não estou atirando em pessoas de verdade?", ele questiona), mas logo internaliza a lógica de funcionamento do mundo e se adapta a ela.

Essa mudança na personalidade e maior conforto no papel de "caubói" fica clara diante de suas interações com o Pistoleiro 
(Yule Bryner), um personagem de poucas falas e trajes escuros (que serão retomados na adaptação seriada, não em um androide, mas sim no personagem humano William, interpretado por Ed Harris). Da primeira vez que eles se encontram, há uma animosidade entre os dois em um saloon, que termina em um duelo. Peter inicialmente hesita, mas se irrita após as provocações mal educadas e dá cabo do desconhecido.

O segundo encontro se dá quando o Pistoleiro ameaça seu amigo John (James Brolin) após invadir a hospedaria onde eles dividem um quarto. O protagonista mais uma vez atira no androide, dessa vez sem hesitação ou dúvida; o gesto vem tão naturalmente que ele mal questiona o motivo de o androide ter ido atrás do seu amigo no quarto onde os dois estavam hospedados. O terceiro encontro se dá no meio da rua, mas dessa vez o resultado é diferente: Peter vê, incrédulo, o amigo ser morto a tiros pelo pistoleiro, e dispara em fuga, o que desencadeia o ato final do filme, com o protagonista sendo perseguido pelo androide implacável ao longo dos diferentes parques.

Outro personagem é o supervisor (Alan Oppenheimer), com a função de representar o lado científico da narrativa: homem de alguma idade e jaleco branco, traz falas recheadas de termos técnicos. É através de suas palavras, com certo didatismo, que temos a primeira antecipação de que algo pode não ir bem; as máquinas são tão complexas que nem mesmo os operários do parque sabem muito bem como elas funcionam.

Ao centralizar a atenção em personagens humanos, dois aspectos importantes se destacam: a focalização externa sobre os 
androides e a priorização do elemento humano na estruturação discursiva. Sobre o primeiro ponto, conhecer os androides sob uma focalização externa não permite ao espectador saber de sua interioridade nem maiores detalhes sobre sua forma de vida; não é possível saber sequer como elas são operacionalizadas; não se tem acesso a quaisquer pensamentos que pudessem vir a ter e, portanto, é impossível compreender o que teria levado à suposta rebelião das máquinas. Teriam os androides ganhado consciência? O mau funcionamento se deve a alguma falha humana, de programação ou manutenção? Ou algum tipo de sabotagem externa, causada por alguma concorrente, para desacreditar a proposta de entretenimento?

As possíveis causas não são importantes para o desenvolvimento da trama tendo em vista o personagem focalizador - Peter quer sobreviver acima de tudo, sem se importar realmente com o que levou àquele resultado. O que fica claro, no tratamento discursivo ao longo do filme, é a sensação de desconhecimento, mistério e pavor diante da ascensão da máquina, retomando um dos conflitos básicos do romance de Mary Shelley. Em Frankenstein, Victor destrói sua segunda criação para evitar o surgimento de uma espécie que ameaçaria o domínio dos seres humanos sobre o planeta, pagando o preço por seu orgulho. No filme Westworld, o elemento humano é priorizado diegética e discursivamente: no enredo, o único sobrevivente que conhecemos é exatamente o protagonista, que consegue resistir aos avanços implacáveis do androide. Em termos discursivos, o seu filtro informativo é o único que nos resta, justamente como o único sobrevivente, dando ao filme 
ares de conto cautelar, que alerta quanto aos perigos do avanço tecnológico desenfreado.

Já a narrativa seriada de Jonathan Nolan e Lisa Joy (2016-) opta por um regime de focalização diverso que tem seu papel na criação da complexidade narrativa - o da focalização múltipla. Além das diferentes linhas temporais que se encontram e os diferentes espaços representados, parte da complexidade se constrói através da focalização adotada pelo seriado: ao estabelecer filtros informacionais diversos, Westworld oferta ao espectador a possibilidade de acompanhar os eventos de perspectivas distintas, cada uma com seus desenvolvimentos e temas que vão se conectando, formando um conjunto emaranhado e complexo.

Essa escolha discursiva abre um leque de possibilidades, criando diferentes núcleos de personagens e efetivamente ampliando o conteúdo abordado pela série, estratégia importante para a criação de um produto que pretende ser bem mais longo (com uma média de dez episódios por temporada, com duração de uma hora cada) e que conta com a interação do público em mídias externas à série, como fóruns e redes sociais.

O seriado possibilita ainda que os androides, aqui chamados de anfitriões, sejam vistos enquanto protagonistas de suas próprias narrativas e não apenas como elementos dentro das histórias de outros, escolha utilizada no texto fílmico. Assim, eles são percebidos enquanto personagens, com seus próprios arcos, mesmo quando aparecem como coadjuvantes. Para tanto, o seriado adota cinco ${ }^{6}$ focos narrativos principais: Dolores Abernathy (Evan Rachel Wood), 6 Notadamente não são os únicos, havendo exceções que acrescentam informações importantes para a compreensão do enredo, mas sim os que ocupam maior tempo de tela. 
Maeve Millay (Thandie Newton), Bernard Lowe (Jeffrey Wright), William (Jimmi Simpson) e o Homem de Preto (Ed Harris). Três destes personagens são anfitriões (embora um deles acredite ser humano durante quase toda a primeira temporada) e dois são humanos, com o destaque de que o William e o Homem de Preto são, na verdade, o mesmo personagem, com uma diferença temporal de trinta anos entre eles.

Essas escolhas colocam os anfitriões em evidência, especialmente considerando que o seriado abre com a narrativa focalizada em Dolores, uma moça jovem, de longos cabelos dourados e vestido azul, envolta em uma aura de otimismo e maravilhamento que será ressignificada ao longo da série e da repetição de seus ciclos narrativos. A primeira sequência exibe a anfitriã com algumas escoriações, os olhos abertos sem expressão, com uma mosca andando pelo seu rosto sem que ela demonstre nenhuma reação. Uma voice over interroga se ela já teria questionado a natureza de sua realidade.

A narrativa se alterna para o dia quase bucólico na vida de Dolores, que vai para a pequena cidade de Sweetwater, reencontrase com Teddy, um amor antigo, apenas para, ao voltar para casa, ver sua família ser morta por bandidos. Os invasores são mortos por Teddy, mas a paz não dura muito, posto que o Homem de Preto aparece e a ataca.

Essa sequência inicial se repetirá, com maior ou menor nível de detalhes iguais, e sofrerá alterações à medida em que os personagens humanos interagem com os anfitriões, de maneira semelhante a um jogo. Outros ciclos são exibidos, como o da 
prostituta Maeve, que recepciona os visitantes recém-chegados no hotel Mariposa, junto com sua amiga, Clementine. Conforme as narrativas avançam, entre idas e vindas aos laboratórios e às salas de manutenção, Dolores e Maeve começam a se lembrar das suas vidas anteriores no parque, os diferentes papéis que ocuparam, bem como as violências perpetradas pelos visitantes.

Além dos históricos atribuídos aos anfitriões através de sua programação, os idealizadores do parque são capazes de perceber que os visitantes conseguem se engajar melhor com anfitriões que pareçam ter histórias que os precedam. Para Florence Favard,

a memória, e mais especificamente, a associação de memórias e traumas como componentes essenciais de uma biografia, leva ela mesma a um melhor entendimento de si. [...] Westworld comumente destaca o fato de que a memória não é apenas o primeiro passo para a consciência, mas também uma ferramenta muito útil para a criação de personagens (grifo nosso) interessantes: eles precisam de um histórico forte o bastante tanto para prender a atenção dos visitantes do parque quanto os espectadores do programa de TV. (FAVARD, 2018, p. 5, tradução nossa)

As memórias como peças fundamentais para o ganho de consciência por parte de personagens maquínicos estão presentes em outros textos da ficção científica, como Blade Runner (Ridley Scott, 1982). No filme, os replicantes (replicants) mais avançados saem de fábrica com memórias implantadas, uma tentativa de tornar as reações dos androides mais genuínas e de facilitar seu aprendizado, dado o curto tempo de validade que têm. Neste universo, utiliza-se o termo para se referir aos androides de 
aparência humana, indicando seu caráter de réplica. O vocábulo se relaciona tanto à ideia de cópia indistinguível quanto à de produção desses seres em massa. Tal escolha atua como uma espécie de distanciamento para os personagens humanos. Já na série Westworld, o termo utilizado é anfitriões (hosts), em oposição aos visitantes (guests). O reconhecimento de subjetividades continua precário (com anfitriões servindo aos convidados), mas nota-se certa intenção em imbricar ainda mais as dúbias fronteiras entre seres humanos e androides.

Diferente dos replicantes, no entanto, os anfitriões dispõem de tempo indeterminado de vida - seus primeiros passos para adquirirem consciência trilham o caminho da memória e o direito de mantê-la, independentemente do quão terríveis elas sejam.

Parte dos sentidos da série são construídos através do tratamento proporcionado à recuperação das lembranças por parte dos anfitriões, o que se dá, a nosso ver, através do uso da narrativa focalizada. Ao entendermos a focalização não apenas como filtro informativo, o ato de recuperar as lembranças de "outras vidas" tem impacto emocional, além de embaralhar a noção temporal dos anfitriões, sendo utilizado a favor da complexidade da trama e das personagens. No caso da personagem Dolores, por exemplo, descobrimos apenas nos episódios finais da primeira temporada que uma boa parte dos eventos que acompanhávamos de sua vida eram, na verdade, um grande flashback, que se encontra à linha temporal do Homem de Preto quando ambos se encontram na cidade onde haviam estado há quase trinta anos atrás. Assim, o espectador experimenta a confusão temporal vivenciada pela própria personagem conforme ela vai clamando suas lembranças, 
que resulta no seu processo de desenvolvimento de consciência. De acordo com Florence Favard, "[Westworld] quer que o espectador faça a si mesmo as mesmas perguntas que Dolores começa a fazer conforme ela pula entre [...] duas eras diferentes" (2018, p. 7, tradução nossa).

É através do tratamento focalizado da narrativa que descobrimos que Dolores repete não só a sua jornada de autoconsciência - na série, materializada pela imagem do labirinto, que se torna uma espécie de jornada destinada apenas aos anfitriões - como também a sina de se voltar contra seu "criador". É ela a perpetradora dos assassinatos de Arnold (Jeffrey Wright) e Robert Ford, sendo o primeiro trinta anos antes do tempo presente da narrativa, e o segundo, no último episódio da primeira temporada. Esse gesto é um lugar-comum encontrado em várias outras obras (os já citados Blade Runner, Frankenstein, além do filme Ex-machina), simbolizando costumeiramente o preço a ser pago pelo orgulho de desafiar a "ordem natural" das coisas, numa espécie de hybris advinda do orgulho.

Essa repetição cíclica na história de Dolores, porém, é ressignificada no último episódio da primeira temporada. O primeiro gesto é ordenado por Arnold, incrustado na programação da androide. O cientista, tal qual Victor Frankenstein, percebe os problemas que a existência de androides conscientes iria desencadear e resolve pôr um termo em sua criação, o parque inteiro - programando os anfitriões a matarem uns aos outros, e, por fim, Dolores a matá-lo. Em Westworld, no entanto, o dilema é diverso: é exatamente por reconhecer a subjetividade dos androides que ele se julga incapaz de comercializar a 
experiência no parque, e, assim, resolve destruir tudo e matarse no processo.

O segundo assassinato se dá em circunstâncias diferentes, embora repita o gesto e, inclusive, o espaço, numa espécie de ironia poética planejada pelo próprio Robert Ford. Aqui, seus gestos já não são mais produtos de programação explícita - ela está completamente consciente quando dispara o tiro. $\mathrm{O}$ que não retira o caráter planejado da morte por parte de Ford, que atua como um grande titereiro. Ele, tal qual Arnold antes dele, preparou todo o palco para o evento, reiterando o gesto de rebeldia mas, agora, Dolores supostamente possui livre arbítrio para decidir a respeito.

A personagem androide, para enfim se libertar e começar a revolução dentro do parque, decide retornar à condição de criatura que se rebela contra seu criador, desestabilizando o status quo do parque e liderando um grande movimento que irá culminar com a busca e destruição dos backups de todos os anfitriões. Destruindo os backups, os androides terão apenas as lembranças da sua própria vivência, as memórias vividas e por eles construídas, e ninguém será capaz de fazer revertê-los a um estado anterior do ganho de sua consciência.

As lembranças também estão atreladas ao esfacelamento de clichês associados a alguns personagens, humanos ou anfitriões. Maeve, por exemplo, é a cafetina de falas irônicas e mordazes, mas logo essa fachada se modifica quando ela começa a se lembrar da morte de sua filha, quando lhe havia sido atribuído um papel anterior dentro do parque, e suas motivações vão mudando. A personagem desperta enquanto está na sala de manutenção e 
passa a apreender o mundo humano, buscando informações e atendo-se ferrenhamente a suas memórias, ao seu aprendizado, desenvolvendo uma identidade própria que vai contra, inclusive, a programação que Ihe foi imposta. Ela passa a provocar a própria morte em ocasiões diversas para que, assim, possa fazer modificações em seu próprio código. Como em um videogame, a personagem utiliza suas várias mortes como meio de aprendizado, embora aqui ela tenha um propósito muito específico - o ganho de sua consciência e a liberdade do parque.

Esse desejo de escape, porém, não parte intrinsecamente dela, mas está programado em camadas profundas de sua personalidade - um outro dado de reflexividade narrativa imbricado na diegese que lembra, tanto ao espectador quanto à personagem, de sua condição de constructo. Mesmo após tantas melhorias e alterações, Maeve descobre que sua história havia sido previamente escrita por Robert Ford e estava programada em seu código. No entanto, prova de que ela está plenamente consciente é sua decisão de, dada a chance de fugir, ficar no parque e procurar a sua filha de uma vida anterior, quebrando sua programação.

As repetidas representações do passado são importantes também para a personagem Bernard Lowe, um dos responsáveis pelo setor de Comportamento e atuante na programação dos anfitriões e na manutenção do parque. Até meados da primeira temporada, assumimos que Bernard é humano, com uma história pregressa de tom trágico: o filho morre ainda criança, vítima de alguma enfermidade, enquanto ele lê um trecho de Alice no país das maravilhas. A perda do filho teria causado um isolamento maior por parte de Bernard, que passou a ficar mais tempo no parque e envolvido com o trabalho. 
Tal qual o próprio personagem, o espectador é levado a pensar que Bernard é humano, dado o tratamento da focalização a partir dele: suas lembranças em torno da morte do filho recebem considerável tempo de tela; o fato de outros personagens trataremno como um humano; os espaços por onde transita, quase sempre em torno das assépticas salas da administração do parque, ou no subsolo, onde os anfitriões descartados são mantidos. Junto com o personagem, descobrimos sua condição de máquina, quando Ford o obriga a assassinar Theresa Cullen (Sidse Babett Knudsen), uma das administradoras. Esse efeito de surpresa é obtido pelo uso do filtro informacional - Bernard passa a perceber suas lembranças como ficções, situação análoga à dos vários anfitriões que ajuda a manter diariamente no parque, e isso faz tanto o personagem quanto o espectador ressignificarem os eventos anteriores da série. Ter ciência de sua condição de ente construído, fazendo-o perceber os elementos em torno dos quais sua identidade gira, não o impede de validar a própria subjetividade: "A dor só existe na mente, é sempre imaginada. Qual a diferença entre a minha dor e a sua?", questiona $\mathrm{o}$ androide.

Diferente dos outros anfitriões, porém, Bernard é revertido para uma versão anterior, e em momentos não apresentados na série, chega a ser refeito, de modo a manter-se mais facilmente controlável. Tanto que é levado a cometer suicídio comandado por Ford. Nota-se, aqui, algumas semelhanças entre Bernard e Arnold: além de serem interpretados pelo mesmo ator, índice de nostalgia por parte de seu criador, o cientista percebe que os anfitriões levariam vidas de sofrimento como ferramentas de entretenimento e por isso, tenta destruir o empreendimento antes de ele ser 
inaugurado, dirigindo, como um diretor de cinema, a própria morte. Bernard, ao notar o potencial de consciência de todos os anfitriões, tenta libertá-los, e é impedido por Ford, que orquestra seu suicídio através do poder de sua voz ${ }^{7}$. O ato do suicídio regido dá aos eventos um certo ar de repetição, porém com outros sentidos adicionados - Arnold quis morrer e encobrir as próprias intenções, ficcionalizando o evento como um desastre científico; Bernard não tinha intenção de fazê-lo, mas foi levado a tal com a criação de uma outra ficção.

No entanto, confirmando os temores e desejos dos seres humanos, Bernard não continua morto, sendo "consertado" por Maeve. O trauma craniano prejudica sua capacidade cognitiva, deixando-o perdido nas linhas temporais dos eventos que vivencia. Mais uma vez, é através da focalização adotada que o espectador experimenta o mesmo sentimento de confusão temporal em relação à trama: Bernard não sabe o que é presente ou passado, e o tratamento discursivo reforça esse efeito, retomando uma estratégia utilizada na primeira temporada através das passagens envolvendo Dolores e William.

Outro uso notável da focalização no seriado vê-se com os personagens William (Jimmi Simpson) e o Homem de Preto ${ }^{8}$. Na

$7 \mathrm{O}$ personagem Robert Ford atua dentro dos limites do parque de forma onisciente e com potencialidades quase divinas: ele parece saber de tudo o que acontece no parque, por ter acesso aos códigos de todos os anfitriões, e, assim, é capaz de controlar suas programações. É através de comandos de voz que os anfitriões podem ser ativados ou desativados, inclusive com palavras que são capazes de conter o alcance emocional de suas reações. Esses índices, além de indicarem o caráter reflexivo da narrativa de Westworld, remetem ao dilema reiterado em tantas narrativas de ficção científica, da posição do ser humano como criador de vida artificial.

8 Tendo em vista o tratamento discursivo utilizado na série, bem como o efeito de confusão que se consegue ao tratar William e o Homem de Preto como distintos, optouse por tratá-los, para efeitos dessa discussão, como dois personagens diferentes. 
primeira temporada, o jovem William é colocado, inicialmente, como o personagem a quem se apresenta o parque e sua proposta, não muito diferente do que acontece no texto fílmico, em que Peter, o protagonista, tem função semelhante. Em alternância aos eventos da vida dos personagens anfitriões, o espectador é capaz de desvelar o parque sob a perspectiva de alguém que nunca esteve lá. Esse filtro narrativo tem dois papéis importantes: um didático e um efeito de projeção. O primeiro, didático beirando ao cautelar, materializa o impacto moral que as vivências no parque podem causar, além de ensinar a "lógica" do espaço para aqueles que não estejam familiarizados com os elementos ou questões abordadas. O segundo, o papel de projeção do espectador, permite que possamos vislumbrar possíveis reações humanas, com as granulações morais inerentes.

Ao longo de sua estada no parque, William se apaixona por Dolores e é apresentado como contraponto a Logan (Ben Barnes), que já naturalizou a ideia de que aqueles eventos, por mais efeitos de realidade que imprimam, não terão consequência real: assim, as diversas violências que comete são permitidas em nome da diversão. O jovem William muitas vezes demonstra horror ante as escolhas do companheiro, mas de maneira paulatina, vai se tornando tão cínico e indiferente quanto ele. Quaisquer moralidades superiores a que se agarrava são implodidas quando ele reencontra Dolores e ela está flertando com um desconhecido - a anfitriã, que adquirira consciência, havia sido revertida para um estado de memória anterior, esquecendo-se dos sentimentos que desenvolveu pelo humano.

Essa queda moral do personagem é manifestada especialmente no seu figurino: inicialmente em tons claros e terrosos, William se 
apresenta como alguém sensato, capaz de um curso de ação centrado e "pé no chão". Além de evitar entrar em conflitos gratuitamente, no início de sua trajetória o personagem quer "jogar com o herói", escolhendo se engajar nas narrativas em que as escolhas morais tenham lados mais claros, como caçar recompensas de bandidos, procurar tesouros, entre outros. No entanto, após a perda de Dolores, ele compreende intimamente a lógica de videogame e passa a encarar o parque como um grande jogo a ser explorado.

O Homem de Preto, por sua vez, é apresentado desde o início como um personagem vilanesco: os trejeitos, as vestes empoeiradas remetendo ao Pistoleiro do filme (em contraposição ao vestido azul impecável de Dolores, que é por ele atacada), sua inquietante determinação em encontrar o labirinto, sem se importar com os anfitriões que precise matar ao longo do caminho. Ele já não apresenta nenhum otimismo ou maravilhamento diante das experiências no parque - quer ir direto ao ponto, aos seus objetivos, que podem até parecer conflitantes. Esse índice é reforçado por Ford em uma conversa no quinto episódio da primeira temporada; o Homem de Preto comenta que sempre sentiu falta de um "vilão real" no parque, ao que Ford responde: "Falta-me a imaginação de sequer conceber alguém como você".

Ao final da primeira temporada, descobrimos que William e Homem de Preto são a mesma pessoa, apartados por mais de 30 anos de diferença. O personagem, então, passa a simbolizar não apenas a queda moral, mas a mortalidade humana. Diferente dos anfitriões, cujas memórias são retiradas, ele deve conviver com o peso de suas escolhas e ações, carregando as marcas do 
rosto enrugado e endurecido, remetendo aos tantos personagens icônicos dos filmes de faroeste. Para Luiz Carlos Oliveira Junior,

ele parece imitar a trajetória dos atores cujo processo de envelhecimento foi documentado pelos westerns em que atuaram. [...] O complemento natural do grande plano geral de paisagem, tão característico ao faroeste, é o primeiríssimo plano do rosto de um ator que envelhece diante da câmera. (OLIVEIRA JÚNIOR, 2020, p. 118)

A lógica interna do parque (com androides que são reiniciados a cada dia, tiros que não têm efeito real nos humanos) cria elementos de sentido semelhantes àqueles presentes em jogos de videogame, que não chegam a ser representados ao longo do seriado mas deixam suas marcas discursivas, tanto nas falas dos personagens quanto em alguns efeitos visuais. Algumas dessas marcas intertextuais, bem como possíveis caminhos analíticos, serão discutidos a seguir.

\section{4. "ESSES PRAZERES VIOLENTOS TÊM VIOLENTOS FINS" - INTERTEXTOS E CONSIDERAÇÕES FINAIS}

Analisar o seriado Westworld como adaptação do filme homônimo trouxe à tona a direção da obra rumo a uma narrativa complexa. Essa mudança amplia o texto primeiro, acrescendo-o de novos personagens e tramas. Tais escolhas parecem adequadas, ao pensarmos que o formato seriado, visando a mais de uma temporada, demanda mais conteúdo.

Não se pode ignorar também os interesses externos às obras. Adaptar um texto já existente, além de ampliar a "aura" (STAM, 2006, p. 22) da obra original, tem o potencial de atrair certo público 
- aquele que teve acesso ao texto-fonte. Incidem ainda outros fatores externos, como a associação ao canal HBO, famoso por altos valores de produção, narrativas complexas e estrelas consolidadas. A ascensão de narrativas do tipo complexa na TV (ou distribuídas por streaming, prática cada vez mais comum no mercado) também está associada ao surgimento de um outro tipo de consumo/ engajamento com o produto, o que Jason Mittel (2015) batiza de forensic fandom, constando de discussões e teorizações por partes de espectadores em diversos fóruns de internet.

Um último fator que contribui à adição de complexidade é a constante presença de intertextos, o que também acontece no texto fílmico analisado. O primeiro e mais gritante é a operacionalização de índices estilísticos associados aos filmes de faroeste. Conforme apontado por Luiz Carlos Oliveira Junior (2020, p. 119), Westworld (Michael Crichton, 1973) mobiliza outros que fazem revisões do gênero, como os tiroteios em câmera lenta presentes em Meu ódio será sua herança (Sam Peckinpah, 1969). Oliveira Junior (2020, p. 119) lembra também que o seriado da HBO, por sua vez, reitera a cidade de Sweetwater, presente em Era uma vez no Oeste (1968, Sergio Leone), filme que também reposiciona personagens femininas ao assumirem papéis de liderança ${ }^{9}$.

Outras interações textuais, mais ou menos sutis, podem ser percebidas ao longo da narrativa seriada, como o nome de um dos idealizadores do parque, Robert Ford. Luiz Carlos de

9 Elizabeth Mullen (2018, p. 5-6) ressalta que o papel revolucionário associado a Dolores e Maeve, embora sejam personagens femininas de destaque, acaba por reforçar certos padrões de gênero (gender). Na leitura da autora, a agência de Dolores é falseada, pois ela, apesar de sua consciência adquirida, acaba seguindo caminhos determinados por outros. Já Maeve, ao quebrar a programação, escolhe a jornada para buscar sua filha fictícia, o que pode consolidar a ideia do amor materno incondicional. 
Oliveira (2020, p. 118) aponta nele uma reverência a John Ford, cineasta famoso por dirigir filmes western. Parece-nos também acertado lembrar o romance de Aldous Huxley, Admirável mundo novo (1932), no qual Ford é adorado como divindade, em uma clara referência ao industrialista Henry Ford. Na distopia de Huxley, os seres humanos são concebidos em laboratório e condicionados a agirem conforme os papéis designados, e qualquer questionamento a respeito das estruturas sociais é desencorajado, até mesmo rechaçado. A posição divina, reiterada pela posição espacial ocupada pelo personagem de Robert Ford (em geral, do alto, observando tudo de sua sala administrativa), é reforçada pela criação de seres à sua imagem e semelhança, além do controle que ele exerce sobre os anfitriões, sendo capaz de programar escolhas, até mesmo falas que parecem improvisadas.

Nota-se os diversos intertextos com os videogames, tanto nas falas dos personagens quanto na estrutura da série. Em diversos momentos, há comparações com a dinâmica dos jogos eletrônicos, em que é possível imergir nas narrativas, porém cientes de que as consequências são meras simulações que aumentam o efeito de imersão - não há risco real envolvido. Na maioria dos jogos eletrônicos de mundo aberto, com um vasto cenário a ser explorado na ordem desejada pelo jogador, há consequências internas ao jogo. A linguagem utilizada nos games o uso de vocábulos como upgrade e cheating aproximam ainda mais essas mídias, como é possível averiguar com a inserção, na terceira temporada, de telas de transição assemelhadas àquelas utilizadas em jogos eletrônicos.

Há intertextos também mais explícitos e que se imbricam em níveis diferentes, como a presença da música tema de Super 
Mario World (Nintendo, 1990), no primeiro episódio da segunda temporada, no piano automático do saloon. No game, o jogador controla Mario, que precisa viajar entre diferentes mundos em uma jornada para salvar a princesa Peach, governante do Mushroom Kingdom. A fórmula do jogo é revisitada ao longo dos anos pela extensa franquia, sendo atualizada conforme as tecnologias avançam, e se baseia em uma repetição de ciclos narrativos com elementos sendo adicionados a cada fase, aumentando a dificuldade. Em relação à série, o intertexto remete às narrativas circulares dos anfitriões, e que também percebem a existência de outros mundos.

Esses índices de narrativa gamificada (ALVES; SOUZA, 2019, p. 420), notamos, faziam-se presentes também no texto-fonte, como a passagem em que o protagonista Peter Martin chega a ser preso por matar, mais uma vez, o androide. Além de haver uma resposta à ação do personagem/jogador, há aí uma deixa para uma outra breve história: o amigo de Peter consegue ludibriar o xerife e entregar explosivos, e depois eles saem em fuga do lugar. Não é incomum que, nos jogos, algumas ações disparem possibilidades narrativas em formato de quests (ou missões, termo corrente no jargão), o que vemos acontecer nessa passagem.

Há, ainda, o uso de câmera subjetiva do Pistoleiro, que exibe, para o espectador, uma tela pixelizada, aparência corriqueira dos jogos na década de 1970 e 1980. Para a audiência não iniciada, as imagens podem causar maior efeito de estranhamento, mas o espectador habituado à estética de jogos eletrônicos tem o potencial de reconhecer mais fortemente o intertexto. 
Por fim, reiteramos que filme e série tratam recorrentes no gênero de ficção científica, com ambas as obras apresentando marcas discursivas coerentes com seu contexto de produção, circulação, consumo e resposta social (BRAGA, 2006). O filme traz uma relação bastante antagônica, sob a focalização exclusivamente humana, enquanto o seriado, buscando tanto a ampliação do texto fílmico quanto uma maior complexidade narrativa, alterna pontos de vista e confunde a percepção temporal de personagens e do espectador, o que contribui para um tipo diferente de engajamento do público, com uma tendência mais analítica e narratológica, procurando antecipações narrativas e, por vezes, decupando o texto.

Essa postura forense por parte da audiência parece ser estimulada pelas plataformas de streaming, posto que o espectador pode ver e rever indefinidamente os títulos, pausando nos momentos em que quiser e até fazendo "maratonas", o que permite a espectação dos episódios de maneira seguida, com os dados narrativos frescos na memória. Jason Mittel (2015) já indicava um comportamento parecido com a venda de mídias físicas, que permite uma experiência semelhante.

Tal modalidade de engajamento com o texto favorece, inclusive, uma percepção dos possíveis intertextos que constituem a obra. Tais intertextos, na forma de referências ou com diálogos mais profundos, contribui para a complexificação narrativa da narrativa seriada.

\section{REFERÊNCIAS}

ALVES, Lynn Rosalina Gama; SOUZA, Maria Carmem Jacob. Bem-vindo ao novo mundo: imergindo na narrativa gamificada da série televisiva Westworld. Revista latinoamericana de ciencias de la comunicación, v. 18, n. 32, 2019. Disponível em: http://revista.pubalaic.org/index.php/alaic/article/view/1624. Acesso em: set. 2020. 
AMARAL, Adriana. Visões perigosas: uma arque-genealogia do cyberpunk. Porto Alegre: Sulina, 2006.

ANAZ, Sílvio. Construindo séries de TV complexas: a concepção diegética de Westworld. Revista Famecos. Porto Alegre, v. 25, n. 2, p. 1-17, maio, junho, julho e agosto, 2018. Disponível em: https://revistaseletronicas.pucrs.br/ojs/ index.php/revistafamecos/article/view/28492. Acesso em: ago. 2020.

BRAGA, José Luiz. A sociedade enfrenta sua mídia. São Paulo: Paulus, 2006. CANDIDO, Antonio. Literatura e sociedade. 6. ed. São Paulo: Nacional, 1980. CLUTE, John; NICHOLLS, Peter. The encyclopedia of science fiction. New York: Martin's Press, 1995.

FAVARD, Florent. The maze wasn't made for you: Artificial consciousness and reflexive narration in Westworld (HBO, 2016-). TV Series, n. 14, 2018. Available at: https://journals.openedition.org/tvseries/3040. Accessed on: $27^{\text {th }}$ Aug. 2020. GENETTE, Gérard. Figuras III. Tradução de Ana Alencar. São Paulo: Estação Liberdade, 2017.

HUTCHEON, Linda. Uma teoria da adaptação. Tradução de André Cechinel. 2. ed. Florianópolis: Editora UFSC, 2013.

MITTEL, Jason. Complex TV: the poetics of contemporary television storytelling. New York and London: NYU Press, 2015. [E-book] Kindle.

MULLEN, Elizabeth. Not much of a rind on you: (de)constructing genre and gender in Westworld (Lisa Joy and Jonathan Nolan, HBO, 2016-). TV Series, n. 14, 2018. Available at: https://journals.openedition.org/tvseries/3304. Accessed on: Sept. 2020.

OLIVEIRA JUNIOR, Luiz. Carlos. Era uma vez em Westworld. ARS (São Paulo), v. 18, n. 38, p. 107-137, 30 de abril, 2020. Disponível em: https://www.revistas. usp.br/ars/article/view/165541. Acesso em: set. 2020.

RÉGIS, Fátima. Nós, ciborgues: tecnologias de informação e subjetividade homem-máquina. Curitiba: Champagnat, 2011.

ROBERTS, Adam. Science Fiction. London: Routledge, 2000.

BURGOYNE, Robert. Film-narratology. In: STAM, Robert; BURGOYNE, Robert; FLITTERMAN-LEWIS, Sandy. New vocabularies in film semiotics. Routledge, 1992. 
STAM, Robert. Teoria e prática da adaptação: da fidelidade à intertextualidade. I/ha do desterro, n. 51, p. 19-53, 2006. Disponível em: https://periodicos.ufsc.br/ index.php/desterro/article/view/2175-8026.2006n51p19. Acesso em: set. 2020. SUVIN, Darko. Metamorphoses of science fiction: on the poetics and history of a literary genre. New Haven, CT: Yale University Press, 1979.

TAVARES, Bráulio. O que é ficção científica. 2. ed. São Paulo: Brasiliense, 1986. 